\title{
OS ASPECTOS JURÍDICOS E PSICOLÓGICOS DA GUARDA COMPARTILHADA: OS DESAFIOS DA ADAPTAÇÃO FAMILIAR
}

\section{THE JURIDICAL AND PSYCHOLOGICAL ASPECTS OF THE SHARED GUARD: THE CHALLENGES OF FAMILY ADAPTATION}

\author{
Jaqueline Moura Sandini Zandoná ${ }^{1}$ \\ Andreia Ayres Gabardo da Rosa ${ }^{2}$
}

\section{RESUMO}

O presente artigo traz a abordagem dos desafios da adaptação familiar na perspectiva dos aspectos jurídicos e psicológicos da guarda compartilhada, dentro de uma abordagem qualitativa, no sentido de dispor de uma concepção exploratória, dedutiva e reflexiva inerente à temática em estudo. Dessa forma, a pesquisa teve como objetivo investigar os desafios da adaptação familiar com relação aos aspectos jurídicos e psicológicos da guarda compartilhada, a partir da perspectiva de acompanhamento da evolução da sociedade contemporânea, frente à necessidade de compreender as nuances que permeiam a questão em lide à luz do Ordenamento Jurídico Brasileiro, mais especificamente da Lei 13.058/2014. O trabalho foi desenvolvido sob a metodologia de pesquisa bibliográfica, com análise de abordagem qualitativa, usando o método exploratório e dedutivo, no sentido de propiciar o aprofundamento e a aplicação dos conhecimentos desenvolvidos nas aulas respectivas. Assim, apresentou-se como resultado do presente trabalho a concepção de que a guarda compartilhada é uma realidade da sociedade contemporânea, que precisa ser estudada e desenvolvida de modo qualitativo e efetivo em âmbito jurídico, propiciando aos genitores a convivência com a criança ou adolescente com igualdade de condições, bem como provendo a esses indivíduos ainda em formação, física emocional e psicológica, as prerrogativas legais instituídas, evitando assim, uma possível alienação parental, e desgastes para todo o núcleo familiar.

PALAVRAS-CHAVE: Guarda Compartilhada. Aspectos Jurídicos. Aspectos Psicológicos.

\footnotetext{
1 Acadêmica do curso de Direito da faculdade Serra do Carmo em Palmas-TO. Email: jaquelinezandona@hotmail.com

${ }^{2}$ Mestre em Psicologia (UFSC). Especialista em Saúde da Família(UFSC) e em Violência Doméstica contra Crianças e Adolescentes (USP). Atualmente é professora de Psicologia Forense e Psicologia Social no curso de Direito da Faculdade Serra do Carmo, psicóloga responsável pelo Núcleo de Atenção Psicopedagógica que compõe o Núcleo de Apoio ao Discente desta instituição. Psicóloga. Email: deiaayres@yahoo.com.br
} 


\section{ABSTRACT}

This article presents an approach to the challenges of family adaptation from the perspective of the legal and psychological aspects of shared custody, within a qualitative approach, in order to have an exploratory, deductive and reflexive conception inherent in the subject under study. Thus, the research aimed to investigate the challenges of family adaptation in relation to the legal and psychological aspects of shared custody, from the perspective of monitoring the evolution of contemporary society, in the face of the need to understand the nuances that permeate the issue in question In the light of the Brazilian Legal Order, specifically of Law 13.058 / 2014. The work was developed under the methodology of bibliographic research, with analysis of qualitative approach, using the exploratory and deductive method, in order to foster the deepening and application of the knowledge developed in the respective classes. Thus, it was presented as a result of the present work the conception that shared custody is a reality of contemporary society, which needs to be studied and developed in a qualitative and effective manner in a juridical context, providing the parents with the child or adolescent with Equality of conditions, as well as providing those individuals still in formation, emotional and psychological, legal prerogatives instituted, thus avoiding a possible parental alienation, and wear and tear for the entire family nucleus.

KEY-WORDS: Shared Guard. Legal Aspects. Psychological aspects.

\section{INTRODUÇÃO}

A base de uma sociedade é o núcleo familiar. No decorrer do tempo e com a evolução socioeconômica da sociedade, este núcleo vem sendo alterado, interferindo diretamente nas relações familiares. A manutenção da família que a princípio era de responsabilidade do homem, passa a ser dividida entre os casais e a mulher amplia sua jornada de trabalho além dos afazeres domésticos, assumindo o mercado de trabalho para contribuir com sua remuneração financeira no sustento familiar.

Adquirindo a autonomia econômica, a mulher conquistou independência social, diminuindo assim a sua sujeição ao cônjuge levando a um aumento no número de divórcios. Paralelamente à conquista do mercado de trabalho pela mulher, o homem ampliou sua contribuição nas tarefas domésticas, desenvolvendo 
mais contato com a prole e se sentindo responsável por tarefas que antes eram somente do sexo feminino (SOUZA, 2011).

No que se refere à guarda dos filhos, a princípio a mais utilizada era a unilateral, ou seja, apenas o pai ou a mãe tomavam decisões em relação à vida cotidiana do filho, sendo que na maioria das vezes a criança ficava com a mãe.

Em decorrência da maior contribuição do homem na criação dos filhos, o pai começou a lutar para fazer parte do cotidiano do filho mesmo depois do divórcio. Surge uma nova fase no Brasil com uma nova lei de Guarda Compartilhada, Lei no 13.058/2014, que entrou em vigor em dezembro de 2014, no qual o juiz determinará que a guarda dos filhos, preferencialmente, seja compartilhada entre o pai e a mãe mesmo quando não houver acordo entre os ex-cônjuges, tendo em vista buscar o que vai ser melhor para a criança ou adolescente.

A nova lei impõe que a guarda seja compartilhada entre os pais, guarda essa que visa fazer com que os direitos, assim como os deveres e as responsabilidades sobre o filho, sejam iguais entre pais e mães, sendo que esse instituto, também visa evitar alienação parental e assegurar à criança que ambos os pais estarão presentes em sua vida.

Diante dos fatos, o objetivo deste trabalho é analisar os aspectos jurídicos e psicológicos da guarda compartilhada e os desafios da adaptação familiar, bem como os seus pontos positivos e negativos, interdisciplinarmente, relacionado a esse tema, haja vista que muitos operadores do direito visam compreender, somente, a literalidade da legislação, terminando o curso sem dar a devida importância para os aspectos psicológicos que a aplicabilidade de determinada lei repercute na sociedade.

Todavia, é imprescindível que, para a efetividade de uma legislação, o operador do direito, na sua aplicabilidade, além de conhecer o texto da lei, tenha também um conhecimento da repercussão desta na área psicológica, principalmente quando se trata de demandas que envolvem o Direito de Família, como é o caso da guarda compartilhada.

Nessa perspectiva, o presente artigo traz uma análise acerca dos aspectos jurídicos e psicológicos da guarda compartilhada, de modo a compreender e explicar 
os desafios da adaptação familiar nesse processo, no sentido de denotar uma concepção exploratória, dedutiva e reflexiva inerente à temática, não cerceando as concepções, tampouco as restringindo, considerado assim a amplitude e complexidade das discussões relativas, mas propiciando a reflexão sobre a necessidade de se desenvolver uma ciência jurídica que venha atender às demandas da sociedade contemporânea.

O trabalho foi desenvolvido sob a metodologia de pesquisa bibliográfica, com análise de abordagem qualitativa, usando o método exploratório e dedutivo, de acordo com o conceituado por Marconi e Lakatos (2010, p.135), a fim de oportunizar o aprofundamento da revisão de literatura e reflexões conduzidas e embasadas na legislação pertinente, doutrinas e jurisprudências relativas ao Direito de Família, tendo como foco o instituto da guarda compartilhada.

Para a execução do estudo, as fontes principais foram as pesquisas bibliográficas de cunho doutrinário e legislativo, concernente à temática, usando no estudo referências primárias e secundárias como: legislações; doutrinas, jurisprudências; dissertações; artigos e matérias relacionadas ao tema, visando a apresentação e compreensão integral da matéria, com base na concepção de Dias (2013); Senise (2012); Severino (2012); Venosa (2012); Souza (2011); Diniz (2011); Sousa (2010); Gomes (2010); Grisard Filho (2002); e Motta (1996); dentre outros estudiosos do ramo do Direito.

Além desta Introdução, Considerações Finais e Referências, o artigo está organizado em quatro principais seções em seu desenvolvimento. Na primeira, está alocada a conceitualização sobre as legislações, referenciais teóricos e embasamentos que respaldam os direitos e deveres relativos à guarda compartilhada.

$\mathrm{Na}$ segunda seção apresentam-se as concepções respectivas aos aspectos contrários e favoráveis da guarda compartilhada, na percepção da família, dos magistrados e psicólogos. Na terceira seção, aborda-se a análise acerca dos fatores determinantes na escolha dos pais pela guarda compartilhada. E na quarta e última seção discorre-se sobre as dimensões psicológicas que mais afetam a família no 
processo de separação, com ênfase para a efetivação da guarda compartilhada, nos moldes da Lei no 13.058/2014.

\section{A GUARDA COMPARTILHADA E SUAS PERSPECTIVAS}

A guarda compartilhada no Brasil é regida, especificamente, pela Lei 13.058/2014, que alterou os artigos, 1.583, 1.584, 1.585 e 1.634 da Lei no 10.406 de 10 de janeiro de 2002 - Código Civil, no sentido de estabelecer o significado da expressão guarda compartilhada, dispondo de sua aplicação.

Assim, a partir da concepção de Souza (2011, p. 146), pode-se dizer que a mudança no Código Civil de 2002 ocorreu como forma de padronizar os aspectos de responsabilidade dos genitores no crescimento e desenvolvimento dos menores, como o sustento e a educação dos filhos, respeitando sempre o melhor interesse da criança e/ou adolescente, independente da dissolução da união justaposta.

A alteração mais relevante na nova norma, conforme disposto no parágrafo $2^{\circ}$ do Art. 1.583, diz que: "§2 $\mathrm{Na}$ guarda compartilhada, o tempo de convívio com os filhos deve ser dividido de forma equilibrada com a mãe e com o pai, sempre tendo em vista as condições fáticas e os interesses dos filhos" (BRASIL, 2014).

Dessa forma, a guarda compartilhada disposta na Lei no 13.058/2014 tem embasamento no Código Civil Brasileiro, o qual dispõe em seu artigo 1.630 que: "os filhos estão sujeitos ao poder familiar enquanto menores", ou seja, é responsabilidade de ambos os pais, o dever da criação e da educação, em todos os âmbitos (BRASIL, 2002).

De mesmo modo, a guarda compartilhada, conforme o disposto no Código Civil Brasileiro e na Lei no 13.058/2014 também tem embasamento na Constituição Federal de 1988, a partir da concepção do princípio da igualdade entre o homem e a mulher, em direitos e deveres, conforme o artigo $5^{\circ}$ : 
I-homens e mulheres são iguais em direitos e obrigações, nos termos desta Constituição;(...) (BRASIL, 1988, p.3).

Destarte, a Constituição Federal impõe meios igualitários aos pais (genitores), na qual a guarda pode ser compartilhada ou poderá permanecer com o pai ou com a mãe, respeitando sempre a proteção ao melhor interesse da criança e/ou adolescente (SOUZA, 2011, p.148).

Outro embasamento da guarda compartilhada na Constituição Federal de 1988 está na proteção da criança e do adolescente, na medida em que tal proteção vem resguardada pelo do art. 227 (caput), que prescreve ser obrigação da família, da sociedade e do Estado proporcionar à criança, com absoluta prioridade, o direito à convivência familiar, bem como protegê-la de toda forma de violência, seja física ou não.

Por conseguinte, o instituto da guarda encontra-se implicitamente previsto na Constituição Federal de 1988 tanto no artigo 227, quanto no 229, que estabelece as responsabilidades dos pais para com os filhos e assegura ainda o direito a toda criança a ter um guardião para protegê-la, prestando-lhe toda assistência na ausência dos genitores (DINIZ, 2011, p. 184).

Na concepção de Grisard Filho (2002, p.155):

A guarda compartilhada atribui aos pais, de forma igualitária, a guarda jurídica, ou seja, a que define ambos os genitores como titulares do mesmo dever de guardar seus filhos, permitindo a cada um deles conservar os seus direitos e obrigações em relação a eles. Neste contexto, os pais podem planejar como convém a guarda física (arranjos de acesso ou esquemas de visitas).

De igual entendimento, Venosa (2012, p. 185) dispõe que:

A ideia é fazer com que pais separados compartilhem da educação, convivência e evolução dos filhos em conjunto. Em essência, essa atribuição reflete o compromisso dos pais de manter dois lares para seus filhos e cooperar de forma conjunta em todas decisões. 
Nessa vertente, a guarda compartilhada é uma inovação no direito de família brasileiro, pois propiciou uma grande mudança instituída às famílias que se dissolveram, no sentido de distribuir melhor as responsabilidades, bem como preservar o interesse dos menores, pois:

E nada obsta a que se decida pela guarda compartilhada, forma de custódia em que, como ensina Maria Antonieta Motta, os filhos têm uma residência principal, mas os pais têm responsabilidades legais sobre eles, ambos os genitores, tendo o outro o direito de visitá-lo periodicamente, mas a responsabilidade legal sobre o filho e pela sua educação seria bilateral, ou seja, do pai e da mãe (DINIZ, 2011, p. 131).

Contudo, pela guarda compartilhada ser um instituto novo no Ordenamento Jurídico Brasileiro, faz-se necessário que sejam feitas análises e discussões a respeito, no sentido de esclarecer pontos sobre sua importância e aplicabilidade, dentro da vertente de resguardar os direitos e os melhores interesses da criança e adolescente, uma vez que o presente Instituto em estudo se apresenta tanto como um direito, quanto como um dever dos pais em relação aos filhos menores.

\section{ASPECTOS CONTRÁRIOS E FAVORÁVEIS DA GUARDA COMPARTILHADA}

No que cabe aos aspectos que tornam a guarda compartilhada favorável ou desfavorável, os estudiosos afirmam que, cada caso deve ser analisado peculiarmente, considerando os fatos e contextos, a fim de designar qual forma de guarda deve ser adotada (GRISARD FILHO, 2002, p.161).

Nesse contexto, concernente aos aspectos desfavoráveis para a aplicação da guarda compartilhada, dentro de uma concordância de entendimento entre pais, magistrados e psicólogos, Souza (2011, p. 149) diz que, quando algum dos genitores apresenta distúrbios ou vícios, os quais possam colocar em risco a integridade e a vida da criança e/ou adolescente, a guarda compartilhada não é favorável, ou seja, não deve ser aplicada. 
Por conseguinte, também é desfavorável a guarda compartilhada quando existem situações comprovadas contínuas de resistência e dissensões entre os pais, como a falta de concordância, de diálogo e decisões unilaterais, tornando impossível um convívio amigável, respeitoso e saudável para a criança e/ou adolescente.

Na mesma concepção, a guarda compartilhada não é favorável, ou seja, não é recomendada quando não existe bom senso e respeito mútuo, entre ambos os genitores, pois:

O juiz deverá procurar a solução prevalente que melhor se adapte ao menor, sem olvidar-se dos sentimentos e direitos dos pais. Em linhas gerais, deve o magistrado atender a vontade dos pais conforme a declinam na separação por mútuo consentimento. Essa decisão também não faz coisa julgada, podendo ser alterada no futuro, havendo necessidade e conveniência. A guarda compartilhada dos filhos por ambos os pais divorciados também deve ser sempre objeto de exames no caso concreto. O projeto de lei do Estatuto das Famílias, no capítulo referente à guarda dos filhos e ao direito de convivência, aconselha 0 juiz a optar pela guarda compartilhada sempre que possível, assegurando-se sempre a convivência de ambos os pais (VENOSA, 2012, p. 187).

Dentro dos aspectos desfavoráveis para a aplicação da guarda compartilhada ainda temos outra desvantagem observada, que é o fato de quando um dos genitores passa a residir distante de onde o menor se encontrar, tornando maior o obstáculo de convivência, sendo que nesse caso, os pais podem deixar de lado o princípio da guarda expresso nos termos da Lei no $13.058 / 2014$, que é o melhor interesse da criança e/ou adolescente (SOUZA, 2011, p. 36).

Já no que cabe aos aspectos que favorecem a aplicação da guarda compartilhada, para os pais ela oferece múltiplas vantagens, pois, propicia participação na guarda da criança e/ou adolescente, participando das decisões e interesses conjuntos, mantendo a continuidade da relação e convívio com os filhos, bem como dividindo as responsabilidades com o outro pai/mãe, disponibilizando espaço também para outras atividades e interesses pessoais dos pais (GRISARD FILHO, 2002, p. 169). 
Por conseguinte, a guarda compartilhada propicia aos pais uma melhor qualidade na relação entre pais e filhos, bem como uma melhor divisão das responsabilidades, maior segurança para os pais e oportunidades melhores de crescimento aos filhos, favorecendo a tomada de decisão comum e a redução dos recursos aos tribunais (PAIXÃO E OLTRAMARI, 2005, p. 64-65).

Concernente aos aspectos favoráveis à guarda compartilhada para os filhos é consenso entre pais, magistrados e psicólogos que a guarda compartilhada favorece o convívio com ambos os genitores, diminui sentimentos de abandono e negligência entre pais e filhos, bem como contribui para o desenvolvimento familiar e social da criança e/ou adolescente com as duas partes, garantindo a continuação dos vínculos e cuidados parentais (SOUZA, 2011, p. 39).

Assim, sobre os aspectos favoráveis à guarda compartilhada, os interesses das crianças e/ou adolescentes estão em primeiro plano, ou seja, é o princípio basilar, conforme a Lei no 13.058/2014, pois é consenso entre família, magistrados e psicólogos que a guarda compartilhada favorece a criança, já que propicia o diálogo e cooperação entre os genitores, visando os interesses dos filhos, imperando a igualdade de direitos e obrigações entre pais e mães, ou seja, homens e mulheres, à luz da Constituição Federal de 1988 (VENOSA, 2012, p. 192).

Dessa forma, nota-se que a guarda compartilhada é um instituto de preserva os direitos e interesses das crianças e adolescentes envolvidos no processo de separação. Assim, ela caracteriza-se como a melhor estratégia da justiça para efetivar a prerrogativa constitucional da igualdade de direitos e obrigações entre os indivíduos.

\section{FATORES DETERMINANTES NA ESCOLHA DOS PAIS PELA GUARDA COMPARTILHADA}

A guarda compartilhada é um instituto jurídico bem estruturado, tanto para os pais quanto para os filhos, pois, no momento da decisão judicial o critério que prevalecerá será o bem-estar dos filhos. Dessa forma, o fator determinante na 
decisão pela guarda compartilhada é o interesse dos filhos (menores), dentro dos termos legais de proteção à criança e/ou adolescente (SOUZA, 2011, p. 151).

Assim, no que cabe aos fatores determinantes na escolha dos pais pela guarda compartilhada está a boa convivência entre ambos os genitores, uma vez que em famílias que não conseguem manter uma convivência em harmonia, a guarda compartilhada não é aplicada, nos termos da Lei nำ13.058/2014 de primar pelos melhores interesses da criança e/ou adolescente, sendo nesse caso, a melhor opção para o filho a guarda única, ou seja, para aquele pai/mãe que tenha melhor condições de oferecer uma vida mais adequada à criança e/ou adolescente, nos termos da lei, físico, psíquico, intelectual, moral e social, bem como possibilitar o contato e convívio do outro pai/mãe com o filho em questão (VENOSA, 2012, p. 188).

Nessa perspectiva, Leite (2003, p. 282) dispõe que:

A guarda conjunta conduz os pais a tomarem decisões conjuntas, levando-os a dividir inquietudes e alegrias, dificuldades e soluções relativas ao destino dos filhos. Esta participação de ambos na condução da vida do filho é extremamente salutar à criança e aos pais, já que ela tende a minorar as diferenças e possíveis rancores oriundos da ruptura. A guarda comum, por outro lado, facilita a responsabilidade cotidiana dos genitores, que passa a ser dividida entre pai e mãe, dando condições iguais de expansão sentimental e social a ambos os genitores.

Assim, como fator determinante está a proteção da criança e/ou adolescente, seus melhores interesses e a predisposição dos pais na participação integral da vida dos filhos, em todos os âmbitos, como um direito e não apenas como obrigação disposta na norma (DINIZ, 2011, p. 78).

Na mesma concepção jurídica, a psicologia aplicada aos interesses jurídicos aduz que:

A guarda compartilhada deve ser vista como uma solução que incentiva ambos os genitores a participarem igualitariamente da convivência da educação e da responsabilidade pela prole. De 
ser compreendida como aquela forma de custódia em que as crianças têm uma residência principal e que define ambos os genitores do ponto de vista legal como detentores do mesmo dever de guardar seus filhos (MOTTA, 1996, p.19).

Desse modo, importa ressaltar que, para que a guarda compartilhada seja aplicada os pais devem revelar interesse e capacidade de cooperação e de educar em conjunto o filho menor, deixando de lado todos os conflitos interpessoais, dispondo de uma relação marcada pela harmonia e pelo respeito, sem disputa e nem conflito entre os pais genitores.

\section{AS DIMENSÕES PSICOLÓGICAS DA GUARDA COMPARTILHADA}

A família é o lugar indispensável para a garantia da sobrevivência e da proteção integral das crianças e adolescentes, desempenhando um papel fundamental na educação formal e informal, na formação de valores éticos e dos laços sócios afetivos (VENOSA, 2012, p.127).

Assim, nos divórcios e separações os membros da família são afetados, principalmente, pela insegurança, o que culmina em conflitos, desavenças, violências, de vários modos, desfazendo a referência familiar daquelas pessoas envolvidas, tanto adultas, quanto crianças e adolescentes (GOMES, 2010, p. 135).

O conflito interparental durante o processo de separação conjugal traz consigo consequências negativas para os filhos, podendo ser um dos fatores com que mais influenciam no desenvolvimento normal de crianças e adolescentes. Dessa forma, o conflito interparental ocorrido nos divórcios tem sido identificado como uma dimensão-chave do sistema familiar, o qual prejudica o seu funcionamento psicológico e os relacionamentos, independentemente da estrutura familiar em que estão inseridos, estando associado a problemáticas comportamentais, emocionais, intelectuais, sociais e do funcionamento familiar (REGO, 2008, p. 18).

Nesse contexto do divórcio, a guarda dos filhos também se torna um litígio, não pelo amor e apego emocional aos filhos, mas pelo momento de perda e dissenção entre os pais, que veem nos filhos uma forma de vingança pelo 
companheiro. Desse modo, uma das dimensões psicológicas que afetam a família no processo de separação, muito em evidência nas varas de Direito de Família e da criança e adolescente é a Síndrome de Alienação Parental (SOUSA, 2010, p. 117).

A Síndrome de Alienação Parental, conhecida pelas siglas SAP e em inglês PAS, é também denominada por alguns doutrinadores como a "Implantação de Falsas Memórias" ou "Abuso do Poder Parental", sendo descrita pela primeira vez em meados do ano de 1980 pelo médico psiquiatra norte-americano Richard Gardner, o qual a definiu como a situação em que a mãe ou o pai de uma criança, após um rompimento amoroso, a treina para romper os laços afetivos com o outro genitor, criando fortes sentimentos de ansiedade e temor em relação ao outro genitor (BROCKHAUSEN, 2012, p.15).

Assim, a Síndrome de Alienação Parental é um tipo de tortura psicológica para com a criança, porém, pouco conhecida na sua profundidade pela sociedade e por grande parte dos profissionais, tais como advogados, juristas e até mesmo psicólogos que tratam das questões de família (SENISE, 2012, p. 41).

Nesse contexto, a Síndrome de Alienação Parental é uma das dimensões psicológicas que afetam as crianças e adolescentes em meio ao processo de separação dos genitores, todavia não é a única, pois também podem ocorrer situações pontuais de alienação parental que estão dissociadas da SAP, conforme se absorve da Lei ํo 12.318/2010.

Nesse aspecto, Serafim (2012, p.12) dispõe que o papel da psicologia em sua interface com o direito é "percorrer a análise e interpretação da complexidade emocional, da estrutura de personalidade às relações familiares e a repercussão desses aspectos na interação do indivíduo com o ambiente".

Destarte, o divórcio e a separação conjugal devem obedecer a um processo legal, respeitando suas complexidades, de acordo com a constituição da família e a vontade dos cônjuges, sendo que a existência de filhos menores implica que o processo seja desenvolvido, tendo em vista o interesse do menor, não significando a ruptura conjugal, uma ruptura parental (SEVERINO, 2012, p. 35).

Contudo, o processo do divórcio pode trazer sentimentos superestimados e de difícil assimilação por um dos cônjuges que não aceitam a nova vida do outro ou 
não aceitam o ato da separação, utilizando o menor como arma contra o cônjuge, causando sequelas que podem ser permanentes, tanto no menor, quanto no cônjuge, ferindo assim, os princípios da dignidade humana, tão bem apregoada pela Norma Suprema do Ordenamento Jurídico Brasileiro (DIAS, 2013, p.145).

A guarda compartilhada possui o viés constitucional dos princípios básicos trazidos pelo constituinte, trazendo expressa a preocupação com a saúde emocional e psicológica das vítimas da separação, sendo que, nessa concepção:

No momento em que ocorre o rompimento do convívio dos pais, a estrutura familiar resta abalada, deixando eles de exercer, em conjunto, as funções parentais. Não mais vivendo com ambos os genitores, acaba havendo uma redefinição de papeis. Tal resulta em uma divisão dos encargos. O maior conhecimento do dinamismo das relações familiares fez vingar a guarda compartilhada ou conjunta, que assegura maior aproximação física e imediata dos filhos com ambos, mesmo quando cessado o vínculo de conjugalidade. É o modo de garantir a forma efetiva a corresponsabilidade parental, a permanência da vinculação mais estrita e a ampla participação destes na formação e educação do filho, a que a simples visitação não dá espaço. $O$ compartilhar da guarda do filho é o reflexo mais fiel do que se entende por poder familiar (DIAS, 2013, p. 454).

Nessa vertente, a guarda compartilhada é a que melhor se ajusta aos interesses da criança e do adolescente, uma vez que, ela terá acesso contínuo com seus pais, contribuindo, para um melhor desenvolvimento, respeitando os sentimentos afetivos já existentes, diminuindo as dimensões negativas do processo de separação dos pais (LÔBO, 2013, p. 178).

Assim, em casos de separação, deve o magistrado priorizar o sistema da guarda compartilhada no qual a responsabilidade de pai e mãe é conjunta, onde dividem o exercício do poder familiar em comum, ainda que ambos não estejam vivendo no mesmo lar (DIAS, 2013, p. 291).

Além da Alienação Parental, existem vários aspectos psicológicos que permeiam o processo de separação conjugal como: Medo, hostilidade, ódio, vingança, depressão e ansiedade, envolvendo desde o casal, quanto às demais pessoas envolvidas, principalmente, as crianças e adolescentes presentes nessa relação (Schettini, 2000 p.44). 
A separação conjugal é uma das experiências mais dolorosas na vida do ser humano de acordo com Schettini (2000 p.44) que dispõe que a separação "é como se, perdendo o outro, ter-se-á perdido uma parte de si. Produz-se uma descompensação", produzindo sentimentos de rebeldia ou conformação, dependendo de como cada indivíduo encara a nova história.

Todavia, deve ser considerado que, em alguns casos, a guarda compartilhada não é possível, sendo que ela não é a solução de todos os problemas que envolvem a separação e a guarda de filhos, mas apenas uma situação ideal que deve ser buscada com equilíbrio e acompanhamento psicológico.

Nesse contexto, observa-se que a separação conjugal envolve um processo de perdas para todos os envolvidos, e que esse momento deve ser encarado como condições para outros ganhos, não se tratando de uma atitude de conformismo, mas sim de uma constatação prática de novas oportunidades e possibilidade de conquistas, sendo a guarda compartilhada uma dessas vertentes que devem ser consideradas e aproveitadas pelos envolvidos nesse processo de mudança familiar.

\section{CONSIDERAÇÕES FINAIS}

O estudo superou a análise respectiva aos desafios da adaptação familiar, abordando os aspectos jurídicos e psicológicos da guarda compartilhada, dentro das perspectivas e prerrogativas do Direito de Família do imperativo de adequação da aplicabilidade da área jurídica às inovações respectivas à Lei no 13.058/2014, atendendo assim o objetivo inicialmente proposto.

Dessa forma, a análise propiciou o entendimento dos desafios inerentes à efetivação da guarda compartilhada tanto na percepção jurídica, quanto psicológica, de acordo com as concepções exploradas em seu desenvolvimento, considerando a amplitude e complexidade das discussões relativas, apresentando como resultado final a reflexão sobre a necessidade de se desenvolver a guarda compartilhada dentro de uma ciência jurídica que venha atender às demandas da sociedade contemporânea. 
Nesse âmbito, o estudo apontou que a Lei $\mathrm{n}^{0}$ 13.058/2014 surgiu no sentido de efetivar o instituto da guarda compartilhada como uma possibilidade jurídica de ser aplicada no Brasil em contraponto à guarda unilateral, dentro de uma concepção e aplicabilidade diferente da trazida pela Lei № $11.698 / 2008$, a qual prometia efetivar a guarda compartilhada, mas não teve êxito porque vinha sendo aplicada de forma equivocada, haja vista que a confusão dos institutos fazia com que os tribunais deixassem de recomendar a guarda compartilhada por entenderem que sua aplicação só se mostrava viável em caso de acordo entre o casal.

Sendo assim, a guarda compartilhada proposta pela Lei $n \cong$ 13.058/2014 caracteriza-se como um bem jurídico, que confere a ambos os pais direitos e responsabilidades iguais, independentemente de quem seja o guardião legal, ou ainda da espécie de litígio entre o casal, tendo sua ênfase nos interesses e necessidades da criança e/ou adolescente, estabelecendo em seus termos o devido significado da expressão de guarda compartilhada, bem como fixando essa modalidade como regra geral após as separações judiciais, na forma de correção e qualificação do que era entendido e aplicado antes de sua promulgação.

Nessa perspectiva, a análise ressaltou a importância de efetivação adequada dos aspectos jurídicos relativos à guarda compartilhada, sem desconsiderar o contexto psicológico dos envolvidos nesse processo, alertando para a aplicação da lei de maneira responsável e qualitativa, principalmente, para as crianças e/ adolescentes inerentes.

O estudo denotou ainda uma característica da sociedade contemporânea no que cabe ao trabalho multidisciplinar, agora delimitado dentro da área jurídica, apontado a importância dessa equipe em âmbito da guarda compartilhada, no sentido de trazer subsídios contextualizados a fim de contribuir para uma atuação jurídica cada vez mais eficiente, deixando nítido qual das casas tem a melhor base de residência para a criança e/ou adolescente, bem como qual é o melhor modo de convivência entre eles e os dois genitores, alcançando uma decisão equilibrada juridicamente.

Doravante, sem o intuito de exaurir a temática, que por sua vez é carecedora de aprofundamento em vários níveis, concluiu-se pela importância da guarda 
compartilhada como um bem jurídico, bem como pela sua aplicação nos moldes jurídicos e psicológicos viáveis e eficazes, de modo a preservar as prerrogativas legais das crianças e adolescentes envolvidos nos respectivos processos.

\section{REFERÊNCIAS}

BRASIL. Constituição (1988). Constituição da República Federativa do Brasil. Disponível em: <www.planalto.gov.br>. Acesso em abril de 2015. Acesso em: 04 dez. 2016.

Lei n. 13.058 de 22 de dezembro de 2014. Altera os arts. 1.583, 1.584, 1.585 e 1.634 da Lei no 10.406, de 10 de janeiro de 2002 (Código Civil), para estabelecer o significado da expressão "guarda compartilhada" e dispor sobre sua aplicação. [internet] Disponível em: <http://www.planalto.gov.br/ccivil_03/_ato20112014/2014/Lei/L13058.htm>. Acesso em: 04 dez. 2016.

Lei n. 10.406, de 10 de janeiro de 2002 (Código Civil) Disponível em: <http://www.planalto.gov.br/ccivil_03/_ato1178-2002/2002/Lei/L10406.htm>. Acesso em: 04 dez. 2016.

BROCKHAUSEN, Tamara. A Lei da Alienação Parental e a Síndrome da Alienação Parental: esclarecimentos. Diálogos. Brasília, 2012.

DIAS, Maria Berenice. Manual de direito das famílias. 6. ed. São Paulo: Revistas dos Tribunais - RT, 2013.

DINIZ, Maria Helena. Curso de direito civil brasileiro: direito de família. 26. ed. São Paulo: Saraiva, 2011. v. 5.

GOMES, C., Fernando, P, \& Oliveira, P. O Novo Regime Jurídico do Divórcio em Avaliação. Coimbra: Centro de Estudos Sociais da Universidade de Coimbra. 2010.

GRISARD FILHO, Waldyr. Guarda Compartilhada: um novo modelo de responsabilidade parental. 2. Ed. São Paulo: RT, 2002.

LÔBO, Paulo. Direito Civil - Obrigações. São Paulo: Ed. Saraiva, 2013.

MARCONI, Marina de Andrade; LAKATOS, Eva Maria. Metodologia do trabalho científico. São Paulo: Editora Atlas, 2010.

MOTTA, Maria Antonieta Pisano. Guarda Compartilhada. Uma Solução possível. Revista Literária do Direito, ano 2, n. 9. p.19, jan./fev. 1996. 
PAIXÃO, Edivane, OLTRAMARI, Fernanda. Guarda Compartilhada dos Filhos. Revista brasileira de direito de família. Porto Alegre, n.32, v.7, out/Nov,2005.

SENISE, Lisboa Roberto. Manual de direito civil, v. 5: direito de família e sucessões / 7. ed. - São Paulo: Saraiva, 2012.

SEVERINO, R. As Rupturas Conjugais e as Responsabilidades Parentais. Mediação Familiar em Portugal. Lisboa: Universidade Católica Editora. 2012.

SERAFIM, Antonio de Pádua; SAFFI, Fabiana. Psicologia e Práticas Forenses. São Paulo: Manole, 2012.

SCETTINI, L. F. Amor perdido de amor: Recife: Bagaço, 2000.

SOUSA, Analicia Martins. Síndrome da alienação parental: um novo tema nos juízos de família. São Paulo: Cortez, 2010.

SOUZA, Camila Barbosa de. Guarda Compartilhada, nova concepção no cuidado de filhos e pais separados. Faculdades Promove. 100 fls. 2011.

VENOSA, Silvo de Salvo. Direito Civil. Direito de Família. Vol. 6, 12aㅡ. ed. Editora Atlas, São Paulo, 2012. 